\title{
Evidential Effort And Risk Assessment In Auditing
}

Allen Blay, Florida State University, USA

Tim Kizirian, California State University, Chico, USA

L. Dwight Sneathen, Jr., Georgia Southern University, USA

\begin{abstract}
This study responds to prior literature highlighting the need for academic research to study the linkage of risks to audit procedures purported in the Audit Risk Model. We use audit workpaper data from a Big 4 firm to examine two significant relationships implicit in authoritative audit guidance: (1) the application of the audit risk model in practice, and the relationship between preliminary risk assessments and audit procedures, and (2) the potential loss of risk information upon risk aggregation suggested in the Audit Risk Model. Our findings indicate that preliminary risk assessments significantly affect planned audit procedures, and the potential for loss of information upon risk aggregation is not to be ignored. These results provide important evidence useful in developing audit policy for linking risk assessments and audit procedures.
\end{abstract}

Keywords: Audit Risk Model, Evidential Planning, Risk Aggregation.

Data Availability: A confidentiality agreement with the data-granting firm precludes the revealing of its identity or disseminating the data.

\section{INTRODUCTION}

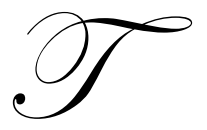

his study uses audit workpaper evidence from a Big 4 accounting firm to provide evidence on the linkage between assessed risks and planned audit effort as prescribed in auditing standards (Bedard, Mock and Wright 1999). We further examine whether inherent and control risks assessed separately explain audit planning decisions (nature, timing and extent) better than a single, aggregated measure of misstatement risk.

Professional standards in auditing dictate that auditors base the allocation of audit procedures on explicit risk assessments about material misstatements in the financial statements (SAS No. 47). The Audit Risk Model (ARM) promotes a risk-focused approach to allocating audit effort. Recent audit failures and the ensuing SarbanesOxley legislation emphasize the importance of adequately understanding client risks and the need for auditors to address significant and pervasive client risks. Admittedly, the ARM provides broad evidential planning guidance and does not uniformly apply to all audit settings. The Auditing Standards Board has recently been examining the risk - effort relation and has decided to retain the ARM with minor revision (e.g., Pany and Whittington 2001). Our findings indicate that risk assessments affect the nature, timing and extent of audit procedures, thus affirming the decision made by the Auditing Standards Board.

Current auditing guidance does not require the separate assessment of inherent and control risk (SAS 47, AICPA 2002). We address the question of whether the aggregation of inherent and control risks into one measure misstatement risk - impedes auditor decision-making. Waller (1994) suggests there must be a gain in effectiveness or efficiency to justify the decomposition of the risk assessment task. While risk aggregation may not equivalently affect all audit planning decisions, if audit effectiveness is compromised, then perhaps the use of an aggregated risk assessment should be reconsidered. While our data pre-dates the Sarbanes-Oxley Act (2002), it indicates that disaggregated measures of inherent and control risk explain nature and extent procedures better than an aggregated 
measure. Our findings may be useful to standard setters seeking better guidance on the relationship between risk assessments and audit effort.

The next section discusses prior literature and develops research hypotheses. Research design and data is discussed in the next section followed by the results, and then the summary and conclusions.

\section{LITERATURE REVIEW AND HYPOTHESIS DEVELOPMENT}

Properly directed audit effort is critical to an effective and efficient audit (Mock and Wright 1993, Davidson and Gist 1996, Bedard et al. 1999). The ARM is included in Generally Accepted Auditing Standards as a normative model to assist auditors in the judgment processes of assessing risks and developing an effective audit plan. Preliminary risk assessments are utilized to determine the appropriate mix of audit evidence (SAS 31; SAS 47). These decisions include the staffing on the engagement, analytical procedures performed, the nature of evidence collected (nature), the timing of evidence collection (timing), and the extent of audit evidence gathered (extent) (Bedard et al. 1999). The focus of this study is limited to the nature, timing and extent of evidence collection (NTE). ${ }^{1}$

NTE

The nature of audit testing addresses the type of testing conducted, therefore influencing the type of evidence gathered. One way to respond to a high-risk client is to require stronger evidence from more effective audit procedures. Prior literature documents that the mix of audit procedures changes with different auditee risk assessments (Bedard and Wright 1994; Messier and Plumlee 1987; Mock and Wright 1993, 1999).

Timing decisions pertain to when tests are performed (e.g., interim or year-end). One way to respond to a high-risk client is to perform substantive tests closer to year end. Srinidhi \& Vasarhelyi (1986) is one of few studies focusing on the timing decision. The dependent variable in their study is a combined measure of internal control reliance and planned timing of audit procedures, which precluded a direct analysis of the timing decision.

Extent pertains to the amount or scope of testing. One way to respond to a high-risk client is to increase the amount of testing for a given assertion. Extent is the most frequently studied of all the planning decisions. Changes in the extent of audit effort appear to be more common than changes in other evidential planning decisions (Bedard et al. 1999; Bedard 1989).

Bedard et al. (1999) provide a summary of the evidential planning literature. They summarize that (1) the nature of audit evidence is generally not found to be statistically related to preliminary risk assessments, (2) very few studies look at the timing of audit procedures, and (3) limited evidence exists of a relationship between certain risk factors and extent. Very few studies use archival workpaper data and the authors are unable to find literature that considers the nature, timing and extent of audit procedures simultaneously. Prior literature has focused on extent and nature decisions.

\section{Inherent And Control Risk}

According to the ARM, auditee risk has two components: inherent and control risk. Authoritative guidance on risk assessments identifies certain audit characteristics that are to be considered when making preliminary assessments of inherent and control risk, but does not clearly indicate the manner in which these factors are to be weighted in the process (e.g., SAS 47, 55, 78).

Inherent risk (IR) is the likelihood of significant misstatements occurring, ignoring the effect of internal control. IR results from the external factors, pressures, and forces brought to bear on the entity as well as from some

\footnotetext{
$1 \quad$ Pany and Whittington (2001) provide a commentary on auditing guidance regarding the linkage between preliminary risk assessments and audit procedures presented in the ARM. They observe that the model in its present form provides limited guidance to the auditor concerning the linkage between auditee risk and the NTE of audit procedures.
} 
internal factors. IR may relate to company-wide conditions or events, and to conditions or events specific to an audit objective, such as the nature of the account balance or class of transactions. When IR is high, we expect that the auditor will require stronger evidence, accumulate more of the evidence at year-end, and perform more testing.

Control risk (CR) is defined as the risk that a material misstatement that could occur in an assertion will not be prevented or detected on a timely basis by internal controls (SAS 47). Factors considered in the assessment of the internal control environment include the degree of competence of personnel, levels of oversight (board of director and audit committee activities), the assignment of authority and responsibility, and management's commitment to the process of providing accurate financial information. When CR is high, the auditor cannot rely on the client's internal controls. Therefore, the auditor could take a more substantive approach, requiring more effective testing preformed at year-end.

\section{Combined Assessments}

The ARM identifies both IR and CR; however, authoritative guidance does not indicate a need to assess these risks separately (SAS 47, AICPA 2002). ${ }^{2}$ Auditors may use these independently assessed risks or they may use an aggregated measure of misstatement risk to determine the mix of evidential procedures required to efficiently and effectively achieve audit objectives (Felix and Kinney 1982). Such flexibility begs the question of whether one method is superior to another. Will an aggregated risk assessment influence audit planning decisions to the same degree as individual IR and CR measures?

Waller (1994) contrasts the integration of two or more component assessments to a single holistic assessment. To justify the decomposition of a risk assessment (e.g., misstatement risk), an overall gain in effectiveness or efficiency must exist (e.g., audit effectiveness). The benefit derived from decomposition must be greater than any additional assessment costs (e.g., separate assessment of IR and CR). Significant risk factors may potentially get masked in the aggregation process that might otherwise have been considered in planning the audit. Consideration of disaggregated risks could provide additional information with little or no increase in analysis cost. Waller (1994) states that policy makers' considerations for decomposed versus holistic assessment should include analysis costs (e.g., assessment time costs), the number and type of various risk factors taken into consideration, and audit effectiveness (e.g., accuracy). Drawing upon the implications of costly analysis, Waller suggests that whether current utilization of the ARM in practice is optimal is an empirical question, and that ample room exists for innovation and improvement through prescriptive research.

Zimbelman (1997) studies the decomposition of risk assessments as it applies specifically to fraud risk. He finds that auditors focus on cues and adjust evidential plans when risk factors change. He suggests that an audit policy that does not require separately assessed IR and CR will not be as likely to draw the auditor's attention to specific risk cues which may be critical in developing an effective audit plan.

Given the lack of prescriptive guidance in the ARM, it is unclear whether practicing auditors consider the risk of material misstatement by combining IR and CR or by considering IR and CR separately when developing the evidential plans. While prior research has found a significant degree of correlation between IR and CR (Messier and Austen 2000; Waller 1993), it is unclear whether the combined or separate risk measurements might differentially affect evidential plans. It is possible, for example, that by aggregating these two into a single risk measure (misstatement risk), the auditor may lose some of the risk information included in the separate measures. In such a situation, the evidential plans might potentially be less effective, hindering the auditor's ability to acquire sufficient, competent evidential matter.

We theorize that the disaggregation of risk assessments will provide better guidance to auditors for audit planning, and more importantly, will contain more information that should be considered in evidential plans.

\footnotetext{
2 SAS 78 indicates the need to assess and document CR separately, however this seems to conflict with the guidance in SAS 47. The Exposure Draft released by the ASB in 2002, did not suggest a change to the existing ARM, affirming SAS 47 guidance that the preliminary assessments of inherent and control risk need not be made individually.
} 
H1a: An aggregated measure of risk (MR) provides auditors with less risk information for making decisions concerning the nature of audit procedures.

H1b: An aggregated measure of risk (MR) provides auditors with less risk information for making decisions concerning the timing of audit procedures.

H1c: An aggregated measure of risk (MR) provides auditors with less risk information for making decisions concerning the extent of audit procedures.

There are two ways in which an aggregated risk measure may provide less risk information. First, the aggregated risk measure should be related to the nature, timing or extent of testing in the same way IR or CR is related. If this is not the case, then perhaps the aggregated risk measure does not carry all the information the separate risk measures contain. Second, if an aggregated MR does not provide the same explanatory power for NTE as a disaggregated IR and CR, then the aggregation would seem to lose some of the risk information.

\section{DATA, VARIABLE MEASUREMENT AND MODEL SPECIFICATION}

\section{Data}

The archival data used in this study is acquired from a Big 4 auditing firm. The firm granted access to its archived audit working papers for a single practice office having a mostly technology client base. Using a random number generator, sample audits were selected from the list of archived engagements containing audit files from 1996 to 1999. The accounting firm provided data for 78 audit engagements, representing 78 different firms. The firm has been auditing these clients for an average of seven years, and 66 of the auditees are publicly traded companies. The data set does not contain any first-year audits. All sampled engagements received unqualified opinions, and none of the clients in the sample have changed their status as going concerns in subsequent periods. There has been no restatement or known allegation of audit failure in subsequent periods. The auditing firm assisted in the coding of variables used in this study and provided a subsequent review to facilitate consistent coding of the data. Each of the 78 firm-year audit observations include the financial statement auditor's inherent and control risk assessments and total audit hours at the revenue cycle level.

Partners of the data-granting firm perceive the revenue portion of the audit to be a more risky audit area, warranting a higher degree of scrutiny. This is corroborated by the fact that $70 \%$ of the Security Exchange Commission Accounting and Auditing Enforcement Releases reviewed surrounded revenue recognition issues (AICPA 2000). ${ }^{3}$ Given the high-risk nature of the revenue cycle, this is an area in which evidential planning decisions should be very sensitive to preliminary risk assessments. This will provide a more powerful setting to study the issues addressed in this paper.

\section{Model Specification And Variable Measurement}

\section{Measuring NTE}

Developing defensible, ex-ante definitions for the NTE of audit procedures is necessary for determining the validity of any proxy used in empirical analysis. While measurement of the extent of audit procedures and the timing of audit procedures is somewhat straightforward, determining an appropriate metric for nature is much more difficult. This study uses the following statement from the 2000 Report of the Public Oversight Board Panel on Audit Effectiveness (AICPA 2000) as principle guidance for deriving appropriate definitions for these constructs:

All other things being equal, the higher the risks...the more extensive the substantive tests need to be, the more persuasive the evidence they provide should be, and the nearer to the balance sheet date they should be performed.

\footnotetext{
3 The data-granting firm considers an account or cycle to be significant if it is critical to the prevention of audit failure, or if its examination will significantly decrease audit firm risk. Several sources corroborate the perceived higher risk of errors and irregularities within the revenue cycle of the audit (e.g., COSO Report 1999).
} 
The use of total audit hours in prior literature fulfills the definition prescribed above for extent and is therefore used in this study. In response to the definition of timing (more year-end work should be done in the presence of higher risks), this study uses a measurement for timing that equals the proportion of total revenue testing hours conducted at the auditee's fiscal year-end.

The above definition of nature emphasizes the persuasiveness of the evidence collected. SAS No. 31 states evidential matter from independent sources is more reliable than information secured solely within the entity. To capture this characteristic, we categorize audit evidence based upon its independence where more independent information is deemed to be more persuasive. Prior literature has used specific audit tests or the number of tests to measure nature (e.g., Mock and Wright 1999). Similar to the number of tests conducted, we cumulate the independence scores for each procedure to develop a score for the total evidence gathered. We believe this metric provides a better measurement of nature based upon the Public Oversight Board Panel on Audit Effectiveness definition. For the sake of clarity, we refer to our nature metric as persuasiveness.

To test our Hypothesis, we employ the following OLS equations:

PERSUASIVENESS $_{\mathrm{i}}=$ RISK $_{\mathrm{i}}+$ TIMING $_{\mathrm{i}}+\mathrm{EXTENT}_{\mathrm{i}}+$ REVRANK $_{\mathrm{i}}+$ TENURE $_{\mathrm{i}}+\mathrm{PUB}_{\mathrm{i}}+\mathrm{IND}_{\mathrm{i}}+\mathrm{e}_{\mathrm{i}}$ TIMING $_{\mathrm{i}}=$ RISK $_{\mathrm{i}}+$ PERSUASIVENESS $_{\mathrm{i}}+$ EXTENT $_{\mathrm{i}}+$ REVRANK $_{\mathrm{i}}+\mathrm{TENURE}_{\mathrm{i}}+\mathrm{PUB}_{\mathrm{i}}+\mathrm{IND}_{\mathrm{i}}+\mathrm{e}_{\mathrm{i}}$ EXTENT $_{i}=$ RISK $_{i}+$ PERSUASIVENESS $_{i}+$ TIMING $_{i}+$ REVRANK $_{i}+$ TENURE $_{i}+$ PUB $_{i}+$ IND $_{i}+e_{i}$

We will use Equation 1 to test Hypothesis H1a. For Equation 1, the dependent variable PERSUASIVENESS is measured using the following classes of evidence independence or persuasiveness: outside, outside/inside, and inside. We categorize audit procedures listed in the revenue cycle of the audit program using a three-point scale (outside evidence equals 3 , outside/inside equals 2 , and inside equals 1). "Outside" evidence is obtained, inspected, or observed completely independent of management. This is considered to be the strongest form of evidence. An example of outside evidence is a cash confirmation sent directly from a bank to the auditor. "Outside/inside" evidence originated from a third party outside of the influence of management but has the potential to be manipulated by management. An example of outside/inside evidence is a bank statement sent by the bank to the auditee. This bank statement originated from the bank but passed through the hands of the auditee, and thus had the potential to be manipulated by the auditee. "Inside" evidence is obtained directly from the auditee. An example is a bank reconciliation prepared by the auditee. PERSUASIVENESS is the average persuasiveness ranking for all procedures listed in the revenue cycle audit program. The higher the value of the variable, the more persuasive (independent) the total evidence collected. We acknowledge this metric is an approximation of this characterization of nature.

We will use Equation 2 to test H1b. The dependent variable for Equation 2, TIMING, equals the proportion of revenue testing hours conducted at the auditee's fiscal year-end relative to total revenue testing hours. ${ }^{4}$ If, for a given audit, 60 percent of substantive hours are conducted at the auditee's fiscal year-end and 40 percent during interim work, then the observation receives a TIMING score of 60.

We will use Equation 3 to test H1c. The dependent variable for Equation 3, EXTENT, equals total revenue cycle audit hours.

The test variable as presented in Equations 1-3 is RISK. This variable will be manipulated to examine several different risk specifications. First, we will examine the influence of auditor assessed inherent risk (IR), and control risk (CR) separately on NTE. Next we will include both risk measures as explanatory variables for NTE. Finally we will examine a combination of these risks as suggested by authoritative guidance. Our metric, misstatement risk (MR), is the multiplicative combination of ranked, auditor-assessed, revenue cycle inherent and control risks (SAS No. 47). The data-granting firm measures and documents inherent and control risk assessments as "low," "medium," or "high." The risks are coded 1 for low, 2 for medium, or 3 for high. ${ }^{5}$

\footnotetext{
$4 \quad$ The data set does not contain audits that changed the proximity of the year-end engagement relative to the auditee's fiscal year-end.

$5 \quad$ The multiplicative combination of IR and CR is consistent with SAS No. 39.
} 
Where PERSUASIVENESS represents the nature of audit evidence we expect that IR will be the dominant risk measure to affect it. We expect the coefficient on IR to obtain a positive value, indicating the auditor requires less persuasive evidence when IR is assessed as low relative to when it is assessed as high. This relationship is intuitive because when management is not trustworthy, in regards to the presentation of financial information, we expect the auditor to collect more independent evidence. The influence of CR on PERSUASIVENESS is not as intuitive. When CR is high the auditor will turn to a more substantive audit approach and increase testing, however the additional evidence may not come from more costly, independent sources. It is unclear whether the auditor will reduce the required independence of audit evidence in order to increase overall testing (extent), or increase the independence of evidence. The inclusion of EXTENT on the right hand side will control for changes in the extent of testing that may result from a high CR, after which we have no directional expectation concerning the relationship between CR and PERSUASIVENESS.

To test the effect of risk aggregation we will also run two models where both IR and CR are used on the right hand side. When IR and CR are both included on the right hand side we will test the incremental effect of CR (IR) beyond IR (CR) on PERSUASIVENESS. The high degree of correlation between IR and CR documented in prior literature might seem to indicate that additional information is not provided when the second risk assessment is added to the regression (Messier and Austen 2000; Waller 1993). We predict that IR and CR will have differential effects on NTE. Our expectation for IR and CR remains unchanged. Next we use misstatement risk (IR*CR) on the right hand side. If MR sufficiently captures the explanatory power of IR and CR then the coefficient of determination $\left(\mathrm{R}^{2}\right)$ of the regression will reflect a similar explanatory power. If the regression with the disaggregated risk measures provides higher explanatory power, then we argue that the combining of IR and CR results in the loss of some critical risk information necessary for EP decisions.

The effect of RISK on TIMING is expected to be consistent across risk measures. When IR or CR are high, the audit response should be to shift testing to the end of the year. Accordingly, we expect the coefficient on IR or CR to obtain a positive value, indicating the auditor requires more evidence collected at year-end when risk is assessed as high relative to when it is assessed as low. Similarly, when both IR and CR are included simultaneously, and when MR is used as the risk measure, we expect positive coefficients.

When EXTENT is the dependent variable, we expect the coefficient on RISK to be positive. When IR or CR is high we expect that auditors will increase overall testing. As discussed with regards to PERSUASIVENESS, a high CR assessment might lead to an increase in overall testing, and there may be a trade off with the PERSUASIVENESS of audit evidence. The inclusion of PERSUASIVENESS as a control variable will isolate the effect of CR on EXTENT. Similarly when MR is included as the RISK measure we expect higher auditee risk will result in greater audit testing.

We include several controls for other influences on the auditor's evidential plan. Due to the potential simultaneous nature of EP decisions, we include the other decision variables as controls (e.g. TIMING and EXTENT are included in Equation 1 to control for possible tradeoffs made in the evidential plan). In addition, prior literature has noted that the length of the auditor-auditee relationship may affect risk assessments and audit effort (O'Keefe, Simunic and Stein 1994; Ashton 1991). This may be due to a familiarity with inherent and control risk factors which reduce the effort necessary to make preliminary risk assessments and conduct tests of controls. We account for this possible effect by including the number of years the auditor has been auditing the auditee (TENURE). As a result of the potential for learning over time, we expect the coefficient on TENURE to be negative (less persuasive evidence, more interim testing, and less overall effort).

To control for auditee size, we include the natural log of book value of total auditee revenue (REVRANK) for the year under audit. Prior literature has shown that the relationship between auditor effort and client size is nonlinear (O'Keefe et al. 1994). While larger firms may have greater oversight, leading to potentially lower misstatement risk assessments and audit effort, they may have more complex control structures and greater decentralization, potentially increasing assessed risk and effort. It is unclear how these effects will aggregate and affect the NTE - REVRANK relationship. Accordingly, we do not have an expectation of the sign on REVRANK. 
Prior research suggests the auditor is more likely to be sued if the auditee is publicly held (e.g., St. Pierre and Anderson 1982). Additionally, incentives to overstate financial standing and results of operations are suggested to be greater for managers of public firms due to market driven compensation packages (O'Keefe et al. 1994). We control for this affect by including an indicator variable (PUB), which we expect to exhibit a positive association with NTE. To control for potential systematic differences in the manner in which audits are conducted between industry groups as identified by the data-granting firm we include IND. IND is an indicator variable representing the two industry categories in our sample. Because we do not have any evidence concerning major changes in audit approach by the data-granting firm between industry groups there is no expectation for the coefficient on IND.

\section{RESULTS}

Table 1 presents descriptive statistics for the variables used in this study. Consistent with prior literature, the correlation between IR and CR is significant and positive $(0.7532, \mathrm{p}=<0.0001)$ (Waller 1993).

Table 1

Descriptive Statistics

\begin{tabular}{|c|c|c|c|c|c|}
\hline \multicolumn{6}{|c|}{$\mathrm{N}=78$} \\
\hline & MEAN & $\begin{array}{l}\text { STANDARD } \\
\text { DEVIATION }\end{array}$ & $\begin{array}{l}\text { QUARTILE } \\
\# 1\end{array}$ & MEDIAN & $\begin{array}{c}\text { QUARTILE } \\
\# 3\end{array}$ \\
\hline IR & 1.5128 & 0.6977 & 1 & 1 & 2 \\
\hline $\mathbf{C R}$ & 1.4359 & 0.6564 & 1 & 1 & 2 \\
\hline MR & 2.5128 & 2.2316 & 1 & 1 & 4 \\
\hline PERSUASIVENESS & 1.6719 & 0.3375 & 1.4 & 1.6 & 2.0 \\
\hline TIMING & 83.50 & 14.3579 & 70 & 80 & 90 \\
\hline EXTENT & 0.0815 & 0.0463 & 0.0488 & 0.0694 & 0.1150 \\
\hline REVRANK & 39.5 & 22.6605 & 20.25 & 39.5 & 58.75 \\
\hline TENURE & 6.0641 & 4.1194 & 3 & 5.5 & 7 \\
\hline PUB & 0.8462 & 0.3631 & 1 & 1 & 1 \\
\hline IND & 0.5641 & 0.4990 & 0 & 1 & 1 \\
\hline
\end{tabular}

Inherent Risk (IR) and Control Risk (CR) are the auditor-documented assessments from the revenue cycle. Misstatement Risk $(\mathrm{MR})=$ Inherent Risk * Control Risk. PERSUASIVENESS is the average persuasiveness score given to audit procedures in the revenue cycle (the persuasiveness score is given on a three level scale: 1 for outside information, 2 for outside/inside information, and 3 for inside information). TIMING is the percentage of substantive tests conducted at the end of the fiscal year of the client. EXTENT is the total hours spent performing test of controls and substantive testing in the revenue cycle deflated by total audit hours. The control variables include: the rank of revenue (REVRANK), Years as Auditor (TENURE), public or private ownership (PUB), and industry categorization (IND).

Table 2 presents OLS regression results for Hypothesis H1a, the influence of risk on the nature (PERSUASIVENESS) of audit procedures. 
Table 2

OLS Regression Analysis

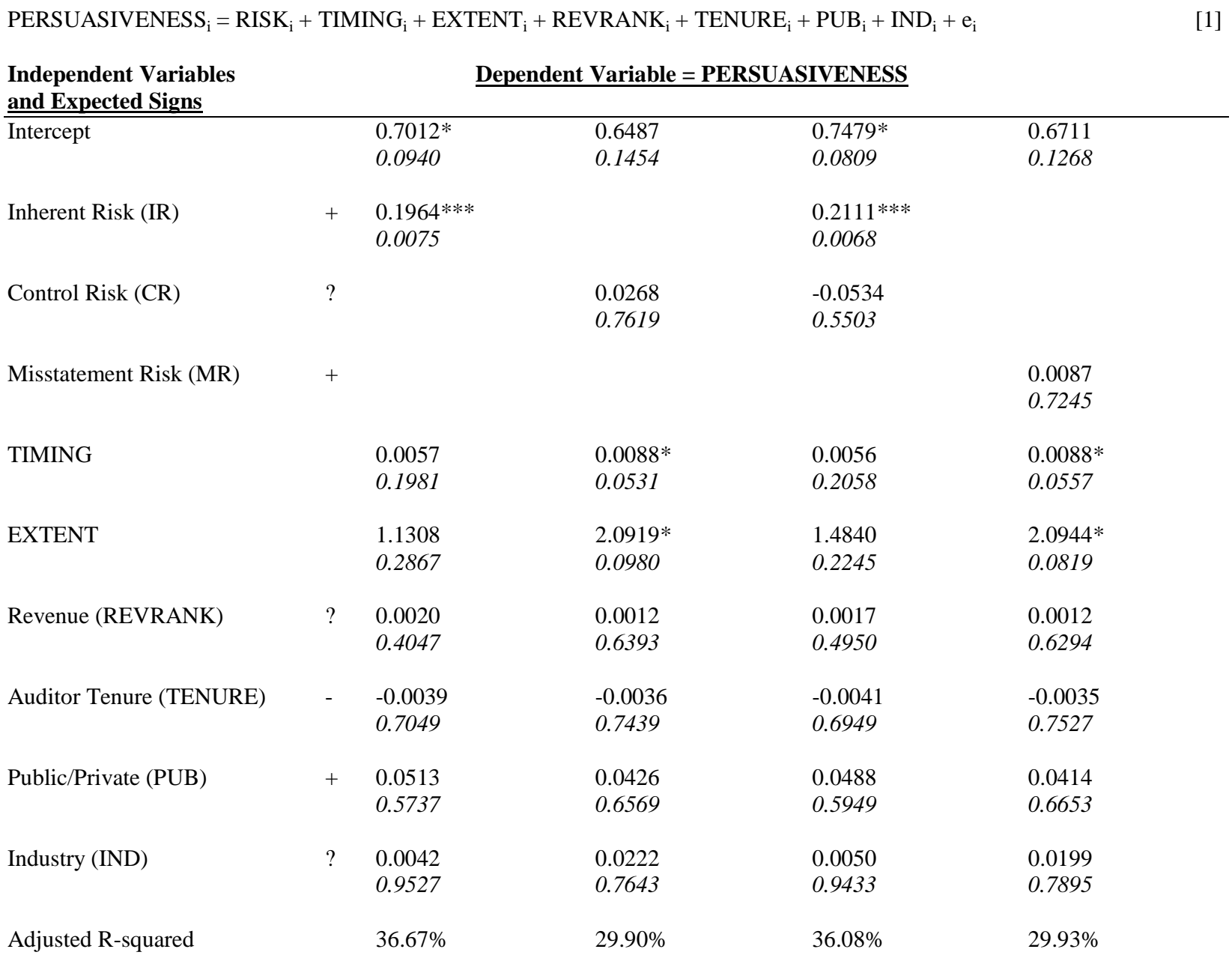

The dependent variable PERSUASIVENESS is the average persuasiveness score given to audit procedures in the revenue cycle (the persuasiveness score is given on a three level scale: 1 for outside information, 2 for outside/inside information, and 3 for inside information). The experimental variable is RISK. We use three different risk measures in these regressions; Inherent Risk (IR), Control Risk (CR), and Misstatement Risk (MR) $=$ Inherent Risk * Control Risk. These are the auditor-documented assessments from the revenue cycle. To control for other planning decisions we include; TIMING, the percentage of substantive tests conducted at the end of the fiscal year of the client, and EXTENT, the total hours spent performing test of controls and substantive testing in the revenue cycle deflated by total audit hours. The control variables include: the rank of revenue (REVRANK), Years as Auditor (TENURE), public or private ownership (PUB), and industry categorization (IND). Statistical significance for parameter estimates are indicated at the $1 \%(* * *), 5 \%(* *)$ and $10 \%(*)$ levels.

The first column presents coefficient estimates when IR is used as the risk measure. In this regression, IR is significant and positive $(2.8719, \mathrm{p}=0.0015)$. This indicates that as inherent risk increases, the auditor responds by collecting more persuasive evidence. The second column presents coefficient estimates when CR is used as the risk measure. Here, $\mathrm{CR}$ is not significant $(-0.2437, \mathrm{p}=0.8094)$. This result seems to indicate that $\mathrm{CR}$ assessments do not affect auditor's decisions regarding the persuasiveness of audit evidence required. 
The third column presents results with both IR and CR included as explanatory variables. IR and CR are both significant, however, the coefficient on IR is positive $(3.5778, \mathrm{p}=0.0003)$ while the coefficient on CR is negative $(-1.8340, \mathrm{p}=0.0744)$. The negative coefficient on $\mathrm{CR}$ is interesting, and may be an indication of an evidential tradeoff which we will further examine in Tables 3 and 4.

Given the results in the third column, results using MR are not surprising. MR is not significant when used as the risk measure $(0.2927, \mathrm{p}=0.3141)$. The significant influence of IR and CR separately are lost when these risk measures are aggregated into MR. With respect to PERSUASIVENESS, these results support H1a.

TIMING and EXTENT obtain significant, positive coefficients in the 4 regressions in Table 2. Similarly, REVRANK is positive and significant in all specifications. ${ }^{6}$ The high adjusted $\mathrm{R}^{2}$ values $(65.27-70.86 \%)$ indicate a large portion of the variability in PERSUASIVENESS is explained by the model. Variance inflation factors (VIFs) do not exceed 4.40 in the Table 2 regressions, indicating multicolinearity does not affect these results. ${ }^{7}$

Table 3 presents results for Hypothesis H1b, the influence of risk on the TIMING of audit procedures.

Table 3

OLS Regression Analysis

\begin{tabular}{|c|c|c|c|c|c|}
\hline $\begin{array}{l}\text { TIMING }_{i}=\text { RISK }_{i}+\text { PERSU } \\
\text { Independent Variables } \\
\text { and Expected Signs }\end{array}$ & & $\begin{array}{r}\mathrm{S}_{\mathrm{i}}+\mathrm{EXTE} \\
\underline{\mathbf{D}}\end{array}$ & $\begin{array}{l}\text { VRANK }_{\mathrm{i}}+\mathrm{T} \\
\text { Variable = T }\end{array}$ & $\mathrm{PUB}_{\mathrm{i}}+\mathrm{INI}$ & \\
\hline Intercept & & $\begin{array}{l}80.7040 * * * \\
<0.0001\end{array}$ & $\begin{array}{l}81.2927 * * * \\
<0.0001\end{array}$ & $\begin{array}{l}80.9633 * * * \\
<0.0001\end{array}$ & $\begin{array}{l}81.7593 * * * \\
<0.0001\end{array}$ \\
\hline Inherent Risk (IR) & + & $\begin{array}{l}3.3218 * \\
0.0955\end{array}$ & & $\begin{array}{l}3.4075 \\
0.1091\end{array}$ & \\
\hline Control Risk (CR) & + & & $\begin{array}{l}.9937 \\
0.6641\end{array}$ & $\begin{array}{l}-0.2935 \\
0.9025\end{array}$ & \\
\hline Misstatement Risk (MR) & + & & & & $\begin{array}{l}0.4644 \\
0.4688\end{array}$ \\
\hline PERSUASIVENESS & & $\begin{array}{l}4.0981 \\
0.1981\end{array}$ & $\begin{array}{l}5.9204 * \\
0.0531\end{array}$ & $\begin{array}{l}4.0687 \\
0.2058\end{array}$ & $\begin{array}{l}5.8459 * \\
0.0557\end{array}$ \\
\hline EXTENT & & $\begin{array}{l}70.6539 * * \\
0.0111\end{array}$ & $\begin{array}{l}82.0195 * * \\
0.0110\end{array}$ & $\begin{array}{l}72.6122 * * \\
0.0245\end{array}$ & $\begin{array}{l}78.2964 * * \\
0.0107\end{array}$ \\
\hline Revenue (REVRANK) & $?$ & $\begin{array}{l}-0.1851 * * * \\
0.0033\end{array}$ & $\begin{array}{l}-0.2041 * * * \\
0.0017\end{array}$ & $\begin{array}{l}-0.1868 * * * \\
0.0040\end{array}$ & $\begin{array}{l}-0.1979 * * * \\
0.0024\end{array}$ \\
\hline Auditor Tenure (TENURE) & - & $\begin{array}{l}-1.0949 * * * \\
<0.0001\end{array}$ & $\begin{array}{l}-1.1225 * * * \\
<0.0001\end{array}$ & $\begin{array}{l}-1.0957 * * * \\
<0.0001\end{array}$ & $\begin{array}{l}-1.1095 * * * \\
<0.0001\end{array}$ \\
\hline Public/Private (PUB) & + & $\begin{array}{l}-0.9581 \\
0.6944\end{array}$ & $\begin{array}{l}-1.1827 \\
0.6340\end{array}$ & $\begin{array}{l}-0.9704 \\
0.6931\end{array}$ & $\begin{array}{l}-1.2112 \\
0.6244\end{array}$ \\
\hline Industry (IND) & $?$ & $\begin{array}{l}-0.1372 \\
0.9422\end{array}$ & $\begin{array}{l}0.1131 \\
0.9531\end{array}$ & $\begin{array}{l}-0.1324 \\
0.9446\end{array}$ & $\begin{array}{l}-0.0268 \\
0.9889\end{array}$ \\
\hline Adjusted R-squared & & $75.04 \%$ & $74.09 \%$ & $74.68 \%$ & $74.21 \%$ \\
\hline
\end{tabular}

$6 \quad$ The results presented in this paper are robust to different size measures including the log of revenue. Marquandt (1980) argues that a multicolinearity problem exists if VIF values exceed 10. 
The dependent variable TIMING is the percentage of substantive tests conducted at the end of the fiscal year of the client. The experimental variable is RISK. We use three different risk measures in these regressions; Inherent Risk (IR), Control Risk (CR), and Misstatement Risk (MR) = Inherent Risk * Control Risk. These are the auditordocumented assessments from the revenue cycle. To control for other planning decisions we include; PERSUASIVENESS, the average persuasiveness score given to audit procedures in the revenue cycle (the persuasiveness score is given on a three level scale: 1 for outside information, 2 for outside/inside information, and 3 for inside information), and EXTENT, the total hours spent performing test of controls and substantive testing in the revenue cycle deflated by total audit hours. The control variables include: the rank of revenue (REVRANK), Years as Auditor (TENURE), public or private ownership (PUB), and industry categorization (IND). Statistical significance for parameter estimates are indicated at the $1 \%(* * *), 5 \%(* *)$ and $10 \%(*)$ levels.

IR is used as the risk measure in the first column, and obtains a significant, positive coefficient $(5.6351, \mathrm{p}=0.0049)$. When we replace IR with CR in the second column, CR obtains a significant, positive coefficient (5.6150, $\mathrm{p}=0.0051)$. When both IR and CR are included as explanatory variables, only IR obtains statistical significance (3.7379, $\mathrm{p}=0.0986)$ while $\mathrm{CR}$ does not $(3.6902, \mathrm{p}=0.1031)$. Based on results in the first and second columns, IR and CR appear to act as substitutes for one another. The column 3 result seems to indicate that IR has a dominant influence on TIMING. VIF's do not exceed 4.37. In light of the results found in columns 1 and 2, the significant coefficient found for MR in column 4 is not surprising $(1.4434, \mathrm{p}=0.0153)$. PERSUASIVENESS is significant and positive in all four regressions in Table 3, and EXTENT is significant and negative in columns 2-4. The results with PERSUASIVENESS as an independent variable would seem to indicate that more persuasive evidence is collected at year-end. The results with EXTENT as an independent variable are consistent with the performance of a more substantive audit. When more reliance is placed on controls, additional controls testing would typically be conducted at interim periods, whereas a more substantive audit would result in more testing done at year-end. Both REVRANK and TENURE are consistently significant and negative in Table 3. Results for REVRANK intuitively indicate that larger clients require more interim testing. The results on TENURE indicate that as the auditor-auditee relationship develops over time more audit effort is conducted during interim periods.

Table 4 presents results for Hypothesis H1c, the influence of risk on the EXTENT of audit procedures. 
Table 4

OLS Regression Analysis

\begin{tabular}{|c|c|c|c|c|c|}
\hline \multirow{2}{*}{$\begin{array}{l}\mathrm{EXTENT}_{\mathrm{i}}=\mathrm{RISK}_{\mathrm{i}}+\mathrm{PER} \\
\text { Independent Variables } \\
\text { and Expected Signs } \\
\text { Intercept }\end{array}$} & & $E$ & $\begin{array}{l}\text { REVRANK } \\
\text { dent Variab }\end{array}$ & $\begin{array}{l}\mathrm{URE}_{\mathrm{i}}+\mathrm{PUB} \\
\text { ENT }\end{array}$ & \\
\hline & & $\begin{array}{l}-0.0883 * \\
0.0603\end{array}$ & $\begin{array}{l}-0.1086^{* *} \\
0.0083\end{array}$ & $\begin{array}{l}-0.1008^{*} \\
0.0157\end{array}$ & $\begin{array}{l}-0.0835^{*} \\
0.0527\end{array}$ \\
\hline Inherent Risk (IR) & + & $\begin{array}{l}0.0243^{* * *} \\
0.0031\end{array}$ & & $\begin{array}{l}0.0079 \\
0.3092\end{array}$ & \\
\hline Control Risk (CR) & + & & $\begin{array}{l}0.0392 * * * \\
<0.0001\end{array}$ & $\begin{array}{l}0.0357 * * * \\
<0.0001\end{array}$ & \\
\hline Misstatement Risk (MR) & + & & & & $\begin{array}{l}0.0102 * * * \\
<0.0001\end{array}$ \\
\hline PERSUASIVENESS & & $\begin{array}{l}0.0143 \\
0.2867\end{array}$ & $\begin{array}{l}0.0184 * \\
0.0980\end{array}$ & $\begin{array}{l}0.0143 \\
0.2245\end{array}$ & $\begin{array}{l}0.0203^{*} \\
0.0819\end{array}$ \\
\hline TIMING & & $\begin{array}{l}0.0012 * * \\
0.0111\end{array}$ & $\begin{array}{l}0.0010^{* * *} \\
0.0110\end{array}$ & $\begin{array}{l}0.0009 * * \\
0.0245\end{array}$ & $\begin{array}{l}0.0011 * * \\
0.0107\end{array}$ \\
\hline Revenue (REVRANK) & $?$ & $\begin{array}{l}-0.0003 \\
0.2109\end{array}$ & $\begin{array}{l}-0.0001 \\
0.7563\end{array}$ & $\begin{array}{l}-0.0001 \\
0.8327\end{array}$ & $\begin{array}{l}-0.0001 \\
0.6227\end{array}$ \\
\hline Auditor Tenure (TENURE) & - & $\begin{array}{l}0.0020 * \\
0.0867\end{array}$ & $\begin{array}{l}0.0017 * \\
0.0974\end{array}$ & $\begin{array}{l}0.0016 \\
0.1099\end{array}$ & $\begin{array}{l}0.0020^{*} \\
0.0645\end{array}$ \\
\hline Public/Private (PUB) & + & $\begin{array}{l}0.0048 \\
0.6387\end{array}$ & $\begin{array}{l}0.0048 \\
0.5897\end{array}$ & $\begin{array}{l}0.0051 \\
0.5654\end{array}$ & $\begin{array}{l}0.0032 \\
0.7325\end{array}$ \\
\hline Industry (IND) & $?$ & $\begin{array}{l}0.0025 \\
0.7486\end{array}$ & $\begin{array}{l}0.0019 \\
0.7803\end{array}$ & $\begin{array}{l}0.0013 \\
0.8469\end{array}$ & $\begin{array}{l}-0.0001 \\
0.9947\end{array}$ \\
\hline Adjusted R-squared & & $57.52 \%$ & $67.23 \%$ & $67.25 \%$ & $63.94 \%$ \\
\hline
\end{tabular}

The dependent variable EXTENT is the total hours spent performing test of controls and substantive testing in the revenue cycle deflated by total audit hours. The experimental variable is RISK. We use three different risk measures in these regressions; Inherent Risk (IR), Control Risk (CR), and Misstatement Risk (MR) = Inherent Risk * Control Risk. These are the auditor-documented assessments from the revenue cycle. To control for other planning decisions we include; PERSUASIVENESS, the average persuasiveness score given to audit procedures in the revenue cycle (the persuasiveness score is given on a three level scale: 1 for outside information, 2 for outside/inside information, and 3 for inside information), and TIMING, the percentage of substantive tests conducted at the end of the fiscal year of the client. The control variables include: the rank of revenue (REVRANK), Years as Auditor (TENURE), public or private ownership (PUB), and industry categorization (IND). Statistical significance for parameter estimates are indicated at the $1 \%(* * *), 5 \%(* *)$ and $10 \%(*)$ levels.

IR is used as the risk measure in the first column, and does not obtain a significant coefficient $(-8.5917, \mathrm{p}=0.6568)$. When we replace IR with CR in the second column, CR obtains a significant, positive coefficient (44.5007, $\mathrm{p}=0.0143)$. When included together as explanatory variables, both IR $(-34.1714, \mathrm{p}=0.0934)$ and CR (58.3007, $\mathrm{p}=0.0035$ ) obtain statistical significance. However, the coefficient on IR is negative while the coefficient on CR is positive.

The negative coefficient on IR merits further discussion. When we consider the Tables 2-4 results, we can bring together an aggregate picture of the influence of IR on evidential effort. When the auditor does not have faith in the representations of management, evidential effort is turned toward more persuasive, year-end evidence. This evidence is apparently collected in lieu of additional tests of detail (extent). 
The CR results in Table 4 are consistent with those in Table 3 as they suggest a substantive audit approach. In light of the results found in the third column, the insignificant coefficient found for MR in column 4 is not surprising $(6.6754, \mathrm{p}=0.2291)$.

\section{SUMMARY AND CONCLUSIONS}

This study examines whether an aggregated measure of misstatement risk explains audit planning decisions as well as the disaggregated assessment of inherent and control risk. The empirical results are based upon archival audit data used to derive metrics for the nature, timing and extent of audit procedures. Our results indicate that in the case of nature and extent, misstatement risk does not provide the same explanatory power that IR and CR separately provide. This appears to be caused by a tradeoff between the nature and extent of audit evidence. IR was significantly related to nature, as expected, and CR was significantly related to extent.

Evidence presented in this study indicates that higher preliminary risk assessments are related to the collection of more persuasive evidence (nature), more year-end evidence (timing), and more evidence (extent). These results are interesting because prior literature has not portrayed these three evidential planning decisions in the same study. Further, nature, timing and extent decisions appear to be interrelated. For example, timing and extent decisions significantly related to the nature of audit evidence in both OLS and SUR analysis. Timing and extent decisions are negatively related, suggesting that an increase in interim testing evidence does not represent a shifting of audit effort from year-end to interim.

The results of this study speak to the scrutiny being placed on the ARM in academic research and by policy setters (Pany and Whittington 2001). This evidence suggests that studies modeling evidential planning decisions as independent may not account for the interdependencies between nature, timing and extent. Future research should consider designing models addressing these three evidential planning decisions (nature, timing and extent). Similarly, policy setters must account for these interdependencies when prescribing audit guidance.

Several factors potentially limit the generalizability of these results. First, the data is drawn from one specific office of one Big 4 firm. While this reduces generalizablity, it also reduces the variability in risk assessments due to the homogeneity of the training and the application of a consistent level of acceptable audit risk. Professional audit standards require auditor training and universal quality control mechanisms to be in place for all audit firms, which may increase the generalizability of the results. Second, the client firms from which this data is drawn are quite different from firms within the mature manufacturing industries examined in prior studies. This study uses high-risk firms with unique business environments. Third, this study focuses on the more risky revenue cycle portion of the audit. While this is a narrow focus, an examination of this risky audit area potentially provides a more powerful setting to study the assessed risk-effort relation implicit in the risk-focused approach.

\section{AUTHOR INFORMATION}

Allen Blay is an Assistant Professor at Florida State University. He teaches in the areas of auditing and judgment and decision-making. His research interests include the effects of risk and financial distress on auditor judgment and decision-making.

Tim Kizirian is a Professor at California State University, Chico. He teaches in the areas of auditing. His research interests include evidential planning in auditing.

L. Dwight Sneathen Jr. is an Assistant Professor at Georgia Southern University. He teaches in the area of financial accounting at both undergraduate and graduate level. His research includes capital markets and audit topics focusing on the impact of firm characteristics on audit planning decisions and outcomes. 


\section{REFERENCES}

1. American Institute of Certified Public Accountants (AICPA). 2000. Panel on Audit Effectiveness Oversight Report and Recommendations. One Station Place, Stamford, CT 06902.

2. American Institute of Certified Public Accountants (AICPA). 2000. Exposure Draft. One Station Place, Stamford, CT 06902.

3. American Institute of Certified Public Accountants (AICPA). 1980. Evidential Matter. Statement on Auditing Standards No. 31. New York, NY: AICPA.

4. American Institute of Certified Public Accountants (AICPA). 1981. Audit Sampling. Statement on Auditing Standards No. 39. New York, NY: AICPA.

5. American Institute of Certified Public Accountants (AICPA). 1983. Omnibus Statement on Auditing Standards. Statement on Auditing Standards No. 45. New York, NY: AICPA.

6. American Institute of Certified Public Accountants (AICPA). 1983. Audit Risk and Materiality in Conducting an Audit. Statement on Auditing Standards No. 47. New York, NY: AICPA.

7. Ashton, A. H. 1991. Experience and error frequency knowledge as potential determinants of audit expertise. The Accounting Review 66 (April): 218-239.

8. Bedard, J. 1989. An archival investigation of audit program planning. Auditing: A Journal of Practice \& Theory (Vol. 9 No. 1, Fall): 57-71.

9. Bedard, J., Mock T., and Wright A., 1999 Evidential Planning in Auditing: A review of the Empirical Research. Journal of Accounting Literature. Volume 18. 1999.

10. Bedard, J. and A. Wright. 1994. The functionality of decision heuristics: reliance on prior audit adjustments in evidential planning. Behavioral Research in Accounting 6 (Supplement): 62-89.

11. Davidson, R. and Gist, W. 1996. Empirical evidence on the functional relation between audit planning and total audit effort. Journal of Accounting Research 34 (Spring): 111-123.

12. Dusenbury, R., J. L. Reimers and S. Wheeler. 1996. An Empirical Study of Belief-Based an d ProbabilityBased Specifications of Audit Risk. Auditing: A Journal of Practice and Theory Fall 1996, Volume 15, Number 2

13. Felix, W. F. and Kinney, W. R. 1982. Research in the Auditor's Opinion Formulation Process: State of the Art. The Accounting Review V57n2, (April): 245-271.

14. Gaumnitz, B., T. Nunamaker, J. Surdick, and M. Thomas. 1982. Auditor consensus in internal control evaluation and audit program planning. Journal of Accounting Research 20 (Autumn): 745-755

15. Greene, W. H. 1997. Econometric analysis. Third Edition. Saddle River, NJ, Prentice Hall.

16. Houston, W., Peters, F. and Pratt, H. 1999. The audit risk model, business risk and audit-planning decisions. The Accounting Review 74 (July): 281-298.

17. Joyce, E.J. 1976. Expert judgment in audit program planning. Journal of Accounting Research (Supplement): 29-60.

18. Marquandt, D. 1980. You should standardize the predictor variables in your regression models. Discussion of: A critique of some ridge regression methods. Journal of the American Statistical Association. 87-91.

19. Messier, W. And D. Plumlee. 1987. The effects of anticipation and frequency of errors on auditors' selection of substantive procedures. Accounting and Business Research 17: 349-358.

20. Mock, T. and J. Turner. 1981. Auditing Research Monograph No. 3: Internal Accounting Control Evaluation and Auditor Judgment. New York: AICPA.

21. Mock, T., and A. Wright. 1993. An exploratory study of auditor evidential planning judgments. Auditing: A Journal of Practice and Theory 12 (Fall): 39-61.

22. Mock, T. and A. Wright. 1999. Are audit program plans risk-adjusted? Auditing: A Journal of Practice \& Theory 18 (Spring): 55-74.

23. O'Keefe, T. B., D. A. Simunic, and M. T. Stein. 1994. The production of audit services: Evidence from a major public accounting firm. Journal of Accounting Research (Autumn): 241-261.

24. Pany, K.J. and O.R. Whittington 2001. Research implications of the Auditing Standard Board's current agenda. Accounting Horizons: 401-411.

25. Quadackers, L., Mock, T., and S. Maijoor. 1996. Audit risk and audit programs: Archival evidence from four Dutch audit firms. The European Accounting Review 5(2): 217-237. 
26. Srinidhi, B., and M. Vasarhelyi. 1986. Auditor judgment concerning establishment of substantive tests based on internal control reliability. Auditing: A Journal of Practice and Theory 6 (Fall): 64-76.

27. St. Pierre, K. and J. Anderson. 1982. An Analysis of Audit Failures Based on Documented Legal Cases. Journal of Accounting, Auditing \& Finance. Boston. Spring 1982.

28. The Committee of Sponsoring Organizations (COSO). 1999. Fraudulent Financial Reporting: 1987-1997 An Analysis of U.S. Public Companies. Copyright 1997 by the National Commission on Fraudulent Financial Reporting.

29. Waller, W. S. 1994. Discussion of Motivating Truthful Subordinate Reporting: An Experimental Investigation in a Two-Subordinate Context. Contemporary Accounting Research (Spring): 721-734.

30. Zellner, A. 1962. An efficient method of estimating seemingly unrelated regressions and tests for aggregation bias. Journal of the American Statistical Association (June): 348-368.

\section{NOTES}

